\title{
EVALUATION OF INTERNAL CONTROL FINANCING MUDHARABAH (CASE STUDY ON BPRS DANA AMANAH SURAKARTA)
}

\author{
Jettie Risniawatie, Endang Masitoh W, Siti Nurlaela \\ Jurusan Akuntansi Fakultas Ekonomi UNIBA Surakarta \\ e-mail: yettierisnia@gmail.com
}

\begin{abstract}
Financing in Islamic banks is one of the backbone of banking activities, because that's where the industry can survive and thrive. A company or institution that has run well should monitor the activities and results. Internal controls can be monitored either by means of a special assessment or aligned with business management. Internal control is required by bank management, because with a good internal control weaknesses will be able to protect people and reduce the likelihood of errors and discrepancies that might occur. This research is a field research conducted in BPRS Dana Amanah in Surakarta. This research method is descriptive qualitative research. This study aims to determine how the internal control procedures of financing and how the application of internal control of financing. The type of data collected in the form of qualitative data and consist of primary data and secondary data. Data collection methods such as interviews, observation, and documentation with qualitative data analysis. Control of BPRS Dana Amanah is reflected in the analysis of financing, Divison of duties, Dual Control, Joint / Dual Custody, Number Control and Balancing Independence. The conclusion of this study is the procedure of financing on the BPRS Trust Fund in accordance with the theory that the financing of the request until the disbursement of funds has no control by each officer. Internal control procedures of BPRS Dana Amanah for financing analysis was consistent with the theory, division of duties is not appropriate because there are geminating duties and functions. Dual control, joint / dual custody, number control, and independence balancing BPRS Dana Amanah have been applied and in accordance with the theory.
\end{abstract}

Key words: Sharia Bank, Mudharabah, Internal Control.

\section{PENDAHULUAN}

Perkembangan perbankan syariah pada era reformasi ditandai dengan disetujuinya Undang Undang No. 10 Tahun 1998. Dalam undang-undang ini diatur secara rinci landasan hukum serta jenis-jenis usaha yang dapat dioperasikan dan diimplementasikan oleh bank syariah. Undang-undang tersebut juga memberikan arahan bagi bank-bank konvensional untuk membuka cabang syariah atau bahkan mengkonversikan diri secara total menjadi bank syariah.

Bank Syariah menurut Rizal Yaya (2013:22) merupakan bank yang menjalankan kegiatan usahanya berdasarkan prinsip syariah yang terdiri atas Bank Umum Syariah (BUS) dan Bank Pembiayaan Rakyat Syariah (BPRS). Bank Umum Syariah adalah bank syariah yang memberikan jasa 
dalam lalu lintas pembayaran, sementara BPRS adalah bank syariah yang melaksanakan kegiatan usahanya tidak memberikan jasa lalu lintas pembayaran. Hal ini sebagaimana disebutkan dalam UndangUndang Perbankan Syariah no. 21 tahun 2008.

Pembiayaan dalam bank syariah merupakan salah satu tulang punggung kegiatan perbankan, karena dari situlah industri perbankan dapat bertahan hidup dan berkembang. Prinsip-prinsip yang mendasari pembiayaan bank syariah antara lain prinsip bagi hasil, prinsip jual beli, prinsip sewa $\mathrm{d}$ an prinsip pengambilan fee. Dari sekian banyak prinsip tersebut, prinsip jual beli dan bagi hasil yang paling menonjol dan menjadi trademark dari produk-produk bank syariah.

Pengendalian internal sangat diperlukan oleh manajemen perbankan, karena dengan pengendalian intern yang baik akan mampu melindungi kelemahan manusia dan mengurangi kemungkinan kesalahan dan ketidaksesuaian yang mungkin terjadi. Pengendalian intern yang baik mampu mendorong tercapainya tujuan organisasi. Kesalahan dalam penyusunan pengendalian intern akan menghasilkan pengendalian yang lemah, sehingga tidak mampu mencegah kemungkinan terjadinya penyelewengan dan kekeliruan dalam perusahaan. Manajemen harus melakukan pengawasan secara terus menerus terhadap efektivitas pengendalian intern perusahaan. Pengendalian intern meliputi struktur organisasi, metode dan tujuan pengendalian intern yang dikoordinasikan untuk menjaga kekayaan perusahaan, mengecek ketelitian dan validitas data akuntansi yang mampu mendorong efisiensi dan mendorong dipatuhinya kebijakan manajemen.

PT. BPR Syariah Dana Amanah adalah perusahaan jasa yang bergerak di bidang perbankan syariah. BPR Syariah Dana
Amanah mempunyai misi memberdayakan ekonomi umat dengan menjunjung prinsip keadilan dan maslahat bersama untuk meningkatkan kesejahteraan masyarakat yang berkelanjutan. Misi ini merupakan tujuan penting bagi perusahaan tetapi dalam pencapaiannya tidak mudah. Setiap perusahaan akan dihadapkan pada berbagai masalah baik dari segi intern maupun ekstern yang dapat menghambat tercapainya tujuan tersebut. Oleh karena itu perlu adanya suatu pengendalian intern yang baik bagi perusahaan agar tujuan perusahaan dapat tercapai sebagaimana yang diharapkan.

Penelitian mengenai pengendalian intern terhadap pemberian pembiayaan mudharabah pada BPR Syariah Dana Amanah Surakarta ini dikarenakan pembiayaan mudharabah pada BPR Syariah Dana Amanah Surakarta merupakan salah satu jenis produk pembiayan yang memerlukan penanganan dan monitoring lebih ketat dibanding dengan jenis pembiayaan yang lain, seperti Murabahah, Hawalah dan Ijarah. Penanganan dan monitoring yang dimaksud disini adalah penanganan dari mulai proses awal analisa pembiayaan hingga mengawal dan memonitor perkembangan usaha selama pembiayaan tersebut masih berjalan. Sehingga peneliti tertarik untuk mengevaluasi pengendalian intern terhadap pemberian pembiayaan mudharabah apakah sudah sesuai dengan komponen-komponen pengendalian intern.

Pemahaman akan praktik pengendalian intern akan sangat menarik bila dipandang dalam perspektif syariah. Hal ini disebabkan konsep bisnis syariah berbeda dari bisnis konvensional. Mengingat bahwa sistem pengendalian intern merupakan kepentingan semua pihak yang terkait, yaitu pemilik dan pengelola bank, masyarakat pengguna jasa bank, Bank Indonesia dan Otoritas Jasa 
Keuangan selaku pembina dan pengawas bank, serta pemerintah, maka studi ini ingin meneliti bagaimana prosedur pemberian pembiayaan mudharabah dan menganalisis pengendalian intern terhadap pembiayaan mudharabah pada BPR Syariah Dana Amanah Surakarta. Berdasarkan hal tersebut, maka penulis tertarik untuk mengkaji tentang "Evaluasi Pengendalian Intern Pembiayaan Mudharabah (Studi Kasus pada PT. Bank Syariah Dana Amanah Surakarta)".

Dari latar belakang yang telah diuraikan, maka dapat dirumuskan masalah yang dikemukakan sebagai berikut: Bagaimana prosedur pembiayaan mudharabah pada PT. BPR Syariah Dana Amanah Surakarta? Apakah prosedur pengendalian intern pembiayaan mudharabah pada PT. BPR Syariah Dana Amanah Surakarta telah sesuai dengan pengendalian intern pembiayaan? Tujuan penelitian yang dilakukan adalah Untuk mengetahui prosedur pembiayaan mudharabah pada PT. BPR Syariah Dana Amanah Surakarta. Untuk mengevaluasi apakah penerapan pengendalian terhadap PT. BPR Syariah Dana Amanah Surakarta telah sesuai dengan pengendalian intern pembiayaan.

\section{METODE PENELITIAN}

Jenis penelitian ini adalah penelitian lapangan yaitu penelitian yang setiap datanya diperoleh secara langsung pada objek penelitian di lapangan (Mardialis, 2003: 89). Penelitian ini dilakukan pada Bank Pembiayaan Rakyat Syariah (BPRS) Dana Amanah Surakarta yang beralamat di Jl. Dr. Rajiman No. 663A Surakarta telp (0271) 725754. Metode penelitian ini adalah penelitian deskriptif kualitatif. Dimana penelitian ini dilakukan dengan mendeskripsikan pengendalian intern pembiayaan mudharabah pada Bank
Pembiayaan Rakyat Syariah (BPRS) Dana Amanah Surakarta.

Penelitian ini memiliki variabel tunggal yaitu pengendalian intern produk Mudharabah PT. BPRS Dana Amanah Surakarta. Variabel tersebut, kemudian dibagi menjadi 5 (lima) komponen yaitu sebagai berikut:

\section{Division of Duties}

Adanya pemisahan antara fungsi-fungsi administrasi dan operasional fungsi penyimpanan. Salah satu unsur dari internal control yang harus dievaluasi sehingga apabila ditemukan pembagian tugas yang tidak memadai/tidak tepat dapat segera disusun langkah-langkah yang harus ditempuh oleh manajemen untuk memperoleh pembagian tugas yang efektif. Pembagian tugas dan tanggung jawab di dalam struktur organisasi yang berkaitan erat dengan pembiayaan ditetapkan sesuai dengan fungsi unit di cabang tersebut, yaitu: Unit recover, Unit Account Officer/Loan officer, dan Unit Loan Administration

\section{Dual Control}

Dual control di sini maksudnya adalah pengecekkan kembali atas suatu pekerjaan yang telah dilakukan oleh petugas sebelumnya untuk menetapkan:

\section{Joint/Dual custody}

Dalam pengamanan penyimpanan folder jaminan pembiayaan dengan menggunakan dua kunci pengamanan dan formulir checklist, pelaksanaannya adalah: Berkas pembiayaan disimpan di dalam filling cabinet di ruang khasanah, dimana kunci untuk masuk ke dalam ruangan dipegang oleh karyawan yang telah ditunjuk oleh Direksi. Untuk jaminan pembiayaan di simpan di dalam almari brankas yang berada di dalam ruang khasanah, diman kunci 
kombinasi untuk membuka diamanahkan kepada dua orang yang ditunjuk oleh Direksi. Penyimpanan atau pengembalian folder mempergunakan formulir checklist memo penyerahan/peminjaman dokumen. Setiap kali folder dipinjam dan dikembalikan, harus mempergunakan satu formulir checklist yang diisi sesuai kebutuhan dan di counter sign oleh dua pihak, yaitu peminjam dan pengelola, selain itu juga di bubuhi tanggal peminjaman dan atau pengembalian.

\section{Number Controls}

Pengawasan intern dapat dilaksanakan melalui sistem penomoran dokumendokumen pada kegiatan pembiayaan dengan tujuan memudahkan pengecekkan dan menghilangkan peluang tindakan manipulasi.

\section{Independence Balancing}

Sistem akuntansi akan menghasilkan keseimbangan otomatis antara saldo suatu rekening dengan rekening lain selama pencatatan, klasifikasi, dan pelaporan transaksi-transaksi tersebut dilakukan dengan benar. Setiap petugas, terutama petugas accounting information process, harus memastikan bahwa sistem, prosedur, dan proses akuntansi telah berjalan sesuai dengan norma-norma akuntansi dan aktif memantau keseimbangan angka-angka laporan keuangan serta lampiran-lampirannya.

Jenis data yang dikumpulkan berupa data kualitatif dan terdiri atas data primer dan data sekunder. Data kualitatif adalah data yang dinyatakan tidak dalam bentuk angka, melainkan dalam kategori, sifat, golongan dan lainnya. Data primer adalah data observasi yang dikumpulkan atau diolah sendiri oleh organisasi yang menerbitkan atau menggunakan data tersebut Data Sekunder.adalah data yang diterbitkan atau digunakan oleh organisasi yang bukan pengolanya. Metode Pengumpulan Data dengan ; Teknik Wawancara Teknik Observasi dan Teknik Dokumentasi

Penelitian ini bersifat deskriptif karena penelitian ini dilakukan untuk memberikan gambaran mengenai pengendalian intern pembiayaan mudharabah yang akan dibandingkan dengan komponen-komponen pengendalian intern secara teori.

\section{HASIL PENELITIAN DAN PEMBAHASAN}

Berdasarkan penelitian yang telah dilaksanakan, diperoleh data yang pada tahap selanjutnya akan dibahas mengenai pengendalian intern pembiayan Mudharabah pada BPRS Dana Amanah sebagai berikut:

Sebagai suatu bank yang aktivitas utamanya berupa pemberian pembiayaan yang diberikan kepada masyarakat. Hal ini dapat menimbulkan resiko pembiayaan bermasalah yang apabila jumlahnya besar dapat mempengaruhi tingkat kesehatan bank. Disamping itu BPRS Dana Amanah yang beroperasi berlandaskan prinsip syariah maka harus konsisten dengan konsep syariah tersebut.

Pengawasan yang dilakukan oleh BPRS Dana Amanah terhadap pembiayaan terutama pembiayaan Mudharabah yang diberikan dilakukan sejak nasabah tersebut melakukan pencairan hingga pembiayaan tersebut lunas. Pengawasan yang dilakukan baik secara aktif maupun pasif seperti halnya perbankan konvensional. Adapun pengawasan aktif yang dilakukan adalah dengan terjun langsung mengunjungi tempat usaha nasabah dengan tujuan untuk mengetahui secara langsung jalannya aktivitas usaha debitur dan penggunaan pembiayaan yang telah diberikan. Apabila debitur dalam usahanya mengalami penurunan, pihak bank akan mencoba menganalisis dan membantu mencari solusi, 
sehingga diharapkan usaha tersebut dapat terselamatkan.

\section{Pengendalian Intern Pembiayaan Mudharabah}

Penerapan pengendalian intern pembiayaan pada BPRS Dana Amanah sebagai berikut;

\section{Division of Duties}

Pada BPRS Dana Amanah belum terlihat jelas dalam pembagian tugas dan tanggung jawab diantara unit pengelola pembiayaan. Unit AO merangkap unit recovery. Memasarkan produk dan jasa-jasa lain, Melakukan upaya penyelesaian pembiayaan untuk pembiayaan bermasalah, Mengidentifikasi kemungkinan ada penurunan tingkat kualitas dan klasifikasi pembiayaan serta melakukan upaya perbaikan, Menagih angsuran kepada nasabah

Unit loand administration merangkap bagian legal. Memproses permohonan pembiayaan yang telah disetujui dengan menyiapkan formulir perjanjian, Mengelola administrasi pembiayaan, Membuat dan mengirimkan laporan pembiayaan, Mengelola dokumen jaminan, Memantau pembiayaan sesuai schedule yang telah dijadwalkan dan mengambil tindakan pengamanan atas agunan dalam hal terjadi keterlambatan angsuran, Mengadministrasikan dokumen-dokumen yuridis untuk semua jenis pembiayaan.

\section{Dual Control}

Pelaksanaan dual control dalam kegiatan pemberian pembiayaan pada BPRS Dana Amanah melekat di dalam pelaksanaan tugas dan tanggung jawab unit-unit terkait yang meliputi.

Account Officer, Menerima permohonan pembiayaan nasabah beserta lampirannya, Meneliti kelengkapan dokumen nasabah terutama yang menyangkut aspek yuridis, aspek keuangan dan aspek jaminan, Melakukan inspeksi ke lokasi nasabah bersama Account Offiser Supervisor.

Account Officer Supervisor (AOS), Meninjau dan melakukan analisis kembali atas permohonan yang diusulan AO, Menyiapkan credit approval package sesuai wewenangnya, Bersama-sama dengan AO mengusulkan kepada direksi untuk menyetujui/menolak permohonan pembiayaan nasabah.

Loan Administration Supervisor, Meneliti kebenaran data debitur, Menerima memo penyerahan dokumen nasabah untuk disimpan ke folder khusus, Memonitor permohonan pembiayaan, Membuat analisis atas permohonan pembiayaan serta menyaipak surat pemberitahuan pembiayaan kepada nasabah dan mempersiapkan perjanjian pembiayaan

Unit Accounting Information, Memverifikasi kebenaran pemasukan data debitur pada computer, Melakukan proses akuntansi secara otomatis melalui komputer.

\section{Jonit/Dual Custody}

BPRS Dana Amanah telah melakukan pengamanan penyimpanan terhadap arsip. Arsip pada BPRS Dana Amanah dikualifikasikan menurut tiga tingkatan yaitu, arsip rahasia, arsip terpakai, dan arsip tidak terpakai. Arsip rahasia disimpan di dalam almari brankas di ruang khasanah, dimana di ruang khasanah terdapat kunci double baik lemari arsip maupun brankasnya. Arsip terpakai disimpan di dalam filling cabinet. Arsip tidak terpakai 
disimpan di jasa penitipan arsip di Klaten.

\section{Number Control}

Pengawasan yang dilakukan oleh BPRS Dana Amanah dengan system penomoran dokumen-dokumen pada kegiatan pembiayaan baik dokumen masuk maupun keluar. Tujuan penomoran ini aar terdapat pengecekan dan menghilangkan kecurangan.

\section{Independence Balancing}

BPRS Dana Amanah melalui accounting melakukan pemantauan secara aktif keseimbangan antara laporan keuangan dengan lampiranlampiran yang ada, yaitu; Keseimbangan angka antara active dan passive neraca harian, bulanan, dan akhir tahun, Keseimbangan angka pospos rekening antara active dan passive pada rekening efektif maupun rekening administrative, Keseimbangan angkaangka pada laporan pembiayaan dengan lampiran neraca debitur dan angka-angka sub buku besar pembiayaan yang diberikan.

\section{Hasil Analisis Data}

Pengendalian pembiayaan pada BPRS Dana Amanah tercermin dalam analisis pembiayaan, Divison of duties, Dual Control, Joint/Dual Custody, Number Control, dan Independence Balancing. Semua pengendalian tersebut dimaksudkan untuk memperlancar proses pemberian pembiayaan pada nasabah yang berhak dan layak untuk mendapatkan pembiayaan serta menjamin pengembalian pembiayaan tersebut yang dilakukan oleh nasabah. a. Analisis Pembiayaan

Pengendalian yang dilakukan oleh BPRS Dana Amanah mencakup pengendalian internal yaitu pengendalian yang dilakukan oleh karyawan atau management BPRS Dana Amanah sendiri, yaitu mencakup adanya pencegahan dan penyelesaian pembiayaan bermasalah. Pada BPRS Dana Amanah mempunyai pedoman pembiayaan sesuai dengan ketentuan yang ditetapkan oleh Bank Indonesia dan Otoritas Jasa Keuangan. Pedoman tersebut berisi tentang ketetapanketetapan dalam pemberian pembiayaan seperti pembiayaan dibuat dengan bentuk perjanjian tertulis, hal ini telah dilaksanakan dengan adanya dokumendokumen yang ada yaitu dokumen akad dan dokumen pengikat lainnya.

Kemudian ketetapan bank dalam menilai calon nasabah menggunakan penilaian $5 \mathrm{C}$ bahwa menurut teori analisis pembiayaan dengan analisis $5 \mathrm{C}$ yaitu Character (Karakter), Capacity (Kemampuan), Collateral (Agunan), Condition of Economy (Kondisi Ekonomi), Capital (Modal). Pada BPRS Dana Amanah dalam menilai calon nasabahnya telah menggunakan penilaian 5C. namun masih terdapat tambahan analia juga.

Pada BPRS Dana Amanah yaitu dengan melihat karakter dari calon nasabahnya, analisa ekonomi, analisa keuangan yang terdiri dari (capacity, capital, repairment, dan risk ability) kemampuan nasabah, collateral menganalisis darimana sumber-sumber pembiayaan yang dimiliki nasabah terhadap usaha yang akan dibiayai oleh bank, selanjutnya caracter calon nasabah, analisis syariah, dan analisis yuridis. 
Menurut Muhammad (2002; 305) dalam pendekatan analisis pembiayaan bahwa perlu adanya pendekatan fungsifungsi bank, artinya bank memperhatikan fungsinya sebagai lembaga intermediary keuangan, yaitu mengatur mekanisme dana yang dikumpulkan dengan dana yang disalurkan, sehingga masing-masing personil harus memahami tugasnya masing-masing agar fungsi bank sebagai lembaga intermediary dapat berjalan.

Ketetapan terakhir yaitu dalam hal penyelesaian pembiayaan masalah yang terjadi dengan melacak keberadaan nasabah kemudian diproses sesuai dengan kebijakan yang ada pada BPRS Dana Amanah. Pada teori,selain prisip 5C terkadang ditambahkan dengan 1C, yaitu Constraint artinya hambatanhambatan yang mungkin mengganggu proses usaha sehingga perlu adanya penyelesaian masalah yang terjadi.

\section{b. Division of Duties}

Pada BPRS Dana Amanah belum terlihat jelas dalam pembagian tugas dan tanggungg jawab diantara unit pengelola pembiayaan. Dalam teori Vietzhal Rivai bahwasannya dalam Division of Duties disebutkan adanya pemisahan antara fungsi- fungsi administrasi dan operasional fungsi penyimpanan agar tercapai internal check yang baik sehingga tidak akan terjadi seseorang melaksanakan pekerjaan dari awal sampai selesai tanpa ada control.

\section{c. Dual Control}

Dalam dual control pada teori yang dipaparkan oleh Vietzhal Rivai dkk, bahwa BPRS Dana Amanah telah melakukan dual control dengan baik sesuai teori. Maksud Dual Cotrol disini adalah pengecekan kembali atas suatu pekerjaan yang telah dilakukan oleh petugas sebelumnya untuk menetapkan:

1) Apakah petugas pertama telah pertindak sesuai dengan batas-batas wewenangnya untuk menangani transaksi yang telah dilakukannya.

2) Apakah transaksi yang telah terjadi tersebut sudah dicatat, dibukukan dan diadministrasikan dengan prosedur yang benar.

3) Apakah transaksi yang terjadi telah diselesaikan dengan prosedur yang benar.

\section{d. Joint/Dual Custody}

Hal ini telah sesuai dengan teori yang dipaparkan oleh Vietzhal Rivai dkk. Bahwa pengawasan intern dapat dilaksanakan melalui penomoran dokumen-dokumen pada kegiatan pembiayaan dengan tujuan memudahkan pengecekan dan menghilangkan peluang manipulasi.

\section{e. Independence Balancing}

BPRS Dana Amanah memalui Accounting melakukan pemantauan secara aktif keseimbangan antara laporan keungan dengan lampiranlampiran yang ada. Menurut teori yang disampaikan Vietzhal Rivai bahwa sistem akuntansi akan menghasilkan keseimbangan otomatis antara sauatu rekening dengan rekening lain selama pencatatan, klasifikasi, dan pelaporan transaksi-transaksi tersebt dilakukan dengan benar. Setiap petugas, terutama accounting harus memastikan bahwa sistem, prosedur dan proses akuntansi telah berjalan sesuai dengan normanorma akuntansi, dan aktif memantau keseimbangan angka-angka laporan keuangan serta lampirannya. 


\section{PEMBAHASAN}

\section{Analisis Pembiayaan}

Pada BPRS Dana Amanah mempunyai pedoman pembiayaan yang berisi tentang ketetapanketetapan dalam pemberian pembiayaan dibuat dalam bentuk perjanjian tertulis, hal ini telah dilaksanakan BPRS Dana Amanah dengan adanya dokumen-dokumen yang ada yaitu antara lain, dokumen akad dan dokumen pengikat. Sehingga BPRS Dana Amanah telah sesuai dengan bank Indoensia dan OJK. Kemduian pada BPRS Dana Amanah yaitu dengan melihat karakter dari calon nasabahnya, analisis ekonomi, analisis keuangan, kolateral menganalisis dari mana sumbersumber pembiayaan yang dimiliki nasabah terhadap usaha yang akan dibiayai oleh bank selanjutnya karakter calon nasabah, analisis syariah, dan analisis yuridis. Hal ini telah sesuai dengan teori bahwa menurut Muhammad (2002) prinsip analisis pembiayaan menggunakan prinsip 5C.

Ketetapan selanjutnya dalam penyusun dan menerapkan prosedur pembiayaan dibuat dalam bentuk diagram untuk memudahkan karyawan dalam memahami dan melaksanakan tugasnya, hal ini sesuai dengan teori Muhammad (2002) bahwa masiangmasing personil harus memahami tugasnya masing-masing agar fungsi bank sebagai lembaga intermediary dapat berjalan.

\section{Divison of Justice}

Masih terdapat perangkapan tugas dan tanggungjawab yaitu pada unit penyelesaian pembiayaan bermasalah dengan unit pengelola pemasaran jasa-jasa atau unit AO dan unit pengelola administrasi, belum jelas pembagian tugas dan wewenangnya. Hal ini belum sesuai dengan teori, bahwasanya dalam division of duties disebutkan adanya Veithzal Rivai dkk pemisahan antara fungsi-fungsi administrasi dan operasional fungsi penyimpanan agar tercapai internal check yang baik sehingga tidak akan terjadi seseorang melaksanakan pekerjaan dari awal hingga akhir tanpa ada kontrol.

\section{Dual control}

Dalam dual control pada teori yang dipaparkan Veithzal Rivai dkk. Adalah adanya pengecekan kembali atas suatu pekerjaan yang telah dilakukan oleh petugas sebelumnya sehingga pda BPRS Dana Amanah telah menerapkan dual control sesuai dengan teori.

\section{Joint/Dual Custody}

Joint/Dual Custody pada teori yang disampaikan oleh Joint/Dual Custody yaitu system pengamanan penyimpanan folder tidak sebatas hanya penyimpanan fisik, namun juga menggunakan dua kunci pengaman dan formulir check list sehingga pada BPRS Dana Amanah sesuai dengan teori yaitu telah menerapkan pengamanan dengan dua kunci pengaman dan formulir check list.

\section{Number Control}

Pengawasan yang dialkukan oleh BPRS Dana Amanah dilakukan dengan system penomoran dokumen pada kegiatan pembiayaan baik dokumen masuk atau keluar. Hal ini telah sesuai 
dengan teori yang dipaparkan oleh Veithzal Rivai dkk bahwa pengawasan intern dapat dilaksnakan melalui system penomoran dokumen-dokumen pada kegiatan pembiayaan guna memudahkan pengecekkan dan menghilangkan peluang tindakan manipulasi.

\section{Independence Balancing}

Menurut teori yang disampaikan oleh Veithzal Rivai dkk bahwa system akuntansi akan menhasilkan keseimbangan otomatis antara saldo suatu rekening denganrekening lain selama pencatatan klasifikasi dan pelaporan transaksi tersebut dilakukan dengan benar. Setiap petugas, terutama petugas accounting harus memastikan bahwa system, prosedur dan proses akuntansi telah berjalan sesuai normanorma akuntansi dan aktif memantau keseimbangan angka-angka laporan keuangan serta lampiran-lampirannya. Sehingga BPRS Dana Amanah telah melakukan pemantauan keseimbangan sesuai teori yang ada.

\section{KESIMPULAN DAN SARAN Kesimpulan}

Setelah melakukan penelitian terhadap pengendalian intern pembiayaan Mudharabah pada BPRS Dana Amanah, berdasarkan hasil analisis dan pembahasan di atas dapat diambil kesimpulan bahwa prosedur pembiayaan mudharabah pada BPRS Dana Amanah telah sesuai dengan teori yaitu dari permohonan pembiayaan sampai pencairan dana telah ada pengendalian oleh masing-masing petugas. Prosedur pengendalian intern pembiayaan mudharabah pada BPRS Dana Amanah untuk analisis pembiayaan telah sesuai dengan teori, division of duties belum sesuai karena masih terdapat perangkapan tugas dan fungsi. Dual control, joint/dual custody, number control, dan independence balancing pada BPRS Dana Amanah telah diterapkan dan sesuai dengan teori.

\section{Keterbatasan Penelitian}

Perolehan data yang diinginkan peneliti belum maksimal hal tersebut berkaitan dengan kebijakan perusahaan dan pertimbngan rahasia perusahaan.

\section{Saran}

Berdasarkan kesimpulan dan keterbatasan penelitian di atas maka penulis memberikan saran, antara lain;

1. BPRS Dana Amanah dalam pengendalian intern sebaiknya terdapat pembagian tugas dan wewenang serta tidak ada perangkapan tugas sehingga pengendaliannya lebih maksimal.

2. Untuk peneliti yang berikutnya sebaiknya meneliti selain pengendalian intern pembiayan mudharabah, dapat juga meneliti tentang pembiayaan murabahah, dan musyarakah.

\section{DAFTAR PUSTAKA}

Antonio, Muhammad Syafii. 2001. Bank Syariah: Dari Teori ke Praktik. Gema Insani, Jakarta.

Basrowi dan Suwandi. 2008. Memahami Penelitian Kualitatif. Rhineka Cipta. Jakarta.

Evi Alviya dan Mohammad Heykal. 2014. Analisa Pengendalian Internal terhadap Pembiayaan Mudharabah Studi Kasus Pembiayaan Mudharabah Bank Syariah Mandiri Cabang Kebon Jeruk. Accounting and Finance Department, 
Faculty of Economic and Communication, BINUS University.

Fadlurrahman. 2009. Analisis Akuntansi pada Pembiayaan Murabahah di BRI Syariah Cabang Yogyakarta, Skripsi Jurusan Ekonomi Islam Sekolah Tinggi Agama Islam Negeri (STAIN). Surakarta.

Hasibuan, Malayu S.P. 2004. Dasar dasar Perbankan. Bumi Aksara. Jakarta.

Ikatan Akuntansi Indonesia. 2009. Standar Akuntansi Keuangan. Salemba Empat, Jakarta.

Martono.2004. Bank dan Lembaga Keuangan Lain. Ekonisia, Yogyakarta.

Maryati, MC. 2001. Statistik Ekonomi dan Bisnis. UPP AMP YKPN Yogyakarta

Milles, Mathew B dan A Michael Hubberman. 1992. Analisis Data Kualitatif Buku Sumber tentang Metode-Metode Baru. Penerbit Universitas Indonesia (UI-Press), Jakarta.

Moeloeng, Lexy, J. 2000. Metodologi Penelitian Kualitatif. PT Remaja Rosdakarya, Bandung.

Muhammad. 2000. Prinsip-prinsip Akuntansi dalam Al Quran. UII Press, Yogyakarta.

Muhammad. 2002. Pengantar Akuntansi Syariah. Salemba Empat, Yogyakarta.

Muhammad. 2005. Pengantar Akuntansi Syariah, Edisi 2. Salemba Empat, Jakarta.
Nabhan, Faqih. 2008. Dasar-dasar Akuntansi Bank Syariah. Lumbung Ilmu, Yogyakarta.

Nabila Shyavira Zakaria, Septarina Prita D.S, dan Siti Maria Wardayati. 2015. Evaluasi Pengendalian Internal Pembiayaan Murabahah Pada BMT Sidogiri Cabang Pembantu Kaliwates (Evaluation of Internal Control Murabahah Financing at BMT Sidogiri Kaliwates Branch). Jurusan Akuntansi, Fakultas Ekonomi, Universitas Jember (UNEJ)

Nadia Maya Sari Dewi. 2012. Analisis Penerapan Struktur Pengendalian Internal terhadap Prosedur Pemberian Pembiayaan untuk Meningkatkan Pencegahan Pengembalian Macet yang Diberikan oleh Bank BNI Syariah Cabang Semarang. Jurusan Akuntansi Fakultas Ekonomika dan Bisnis Universitas Diponegoro

Raga Fahmy Darmawan, Anantawikrama Tungga Atmadja, M. Nyoman Ari Surya Darmawan. 2015. Analisis Sistem Pengendalian Intern dalam Pembiayaan Implan pada PT. Bank Syariah Mandiri (Studi Kasus Pada PT. Bank Syariah Mandiri Kantor Cabang Pembantu Buleleng). Jurusan Akuntansi Program S1 Universitas Pendidikan Ganesha Singaraja, Indonesia

Rivai, Veithzal, dkk. 2007. Bank and Financial Institution Management Conventional and Sharia System. Raja Grafindo Persada. Jakarta. 
Sherly Tamira dan Muhammad Yusuf. 2015. Evaluasi Pengendalian Internal atas Pembiayaan Musyarakah pada PT Bank Muamalat Indonesia Tbk. Universitas Bina Nusantara tahun.

Sugiyono. 2008. Metode Penelitian Bisnis. Alfabeta, Bandung.

Suwandi dan Basrowi. 2008. Memahami Penelitian Kualitatif. Rineka Cipta, Jakarta.

Suwardjono. 2008 Teori Akuntansi: Perekayasaan Pelaporan Keuangan, Eidsi Ketiga, BPFE Yogyakarta.

Yaya, Rizal, dkk. 2009. Akuntansi Perbankan Syariah, Salemba Empat, Jakarta. 